\title{
Bioactive Compounds and Traditional Herbal Medicine: Promising Approaches for the Treatment of Dementia
}

This article was published in the following Dove Press journal: Degenerative Neurological and Neuromuscular Disease

\author{
Nafaa Alzobaidi ${ }^{1}$ \\ Huma Quasimi ${ }^{2}$ \\ Nasr A Emad (D) ${ }^{3}$ \\ Abdulsalam Alhalmi $\mathbb{D D}^{4}$ \\ Maaz Naqvi' \\ 'Department of Pharmacology, Hamdard \\ Institute of Medical Sciences and \\ Research (HIMSR), Jamia Hamdard, New \\ Delhi, India; ${ }^{2}$ Department of Physiology, \\ Hamdard Institute of Medical Sciences \\ and Research (HIMSR), Jamia Hamdard, \\ New Delhi, India; ${ }^{3}$ Department of \\ Pharmaceutics, School of Pharmaceutical \\ Education \& Research, Jamia Hamdard, \\ New Delhi, India; ${ }^{4}$ Department of \\ Pharmaceutics, College of Pharmacy, \\ Aden University, Aden, Yemen
}

\begin{abstract}
Dementia is a term that encompasses a group of clinical symptoms affecting memory, thinking and social abilities, characterized by progressive impairment of memory performance and cognitive functions. There are several factors involved in the pathogenesis and progression of dementia, such as old age, brain ischemia, toxin exposure, and oxidative stress. There are extensive similarities between dementia and Alzheimer's disease (AD) either in clinical manifestations or experimental animal models. AD is the most dominant form of dementia, characterized by the accumulation of beta-amyloid protein and cholinergic neurotransmission deficits in the brain. Currently available medications for the treatment of dementia, such as choline esterase inhibitors, N-methyl-D-aspartate (NMDA) antagonists (memantine), have short-term efficacy and only relieve symptoms rather than targeting the main underlying pathogenesis. Several animal studies and clinical trials are being conducted to provide a rational approach to these medicinal plants in the prevention or treatment of memory deficits. This review highlights the potential effects of medicinal plants and their derived lead molecules, and explains the related mechanisms and effects reviewed from published literature as major thrust aspects and hopeful strategies in the prevention or treatment of dementia.
\end{abstract}

Keywords: cognitive impairment, Alzheimer's disease, vascular dementia, dementia, medicinal plants, bioactive compounds

\section{Introduction}

Dementia is a term that encompasses a group of clinical symptoms affecting memory, thinking and social abilities, characterized by progressive impairment of memory performance and cognitive functions. It has emerged as a major social and medical challenge that calls for urgent measures to establish its underlying pathogenesis and therapeutic interventions. There are several factors involved in the pathogenesis and progression of dementia, such as old age, brain ischemia, toxin exposure, and oxidative stress. Globally, around 50 million people are believed to be lived with dementia, with nearly 7.7 million new annual cases. The majority of them are poorly diagnosed and belong to low- and middle-income countries. ${ }^{1}$ Dementia is considered one of the most common causes of death in high-income countries. ${ }^{2}$ Although dementia is usually considered a disease of the elderly, the number of cases between 40 and 60 years of age rises rapidly. ${ }^{3}$ In spite of the rapid progress in the development of synthetic drugs targeting memory loss, the demand for alternative or complementary medicine is also growing globally, and it should be given great attention. Herein, we review the pivotal
Correspondence: Abdulsalam Alhalmi Department of Pharmaceutics, College of Pharmacy, Aden University, Aden, Yemen Email aa.abdulla@pharm.adenuniv.com
Degenerative Neurological and Neuromuscular Disease 2021:I I I-|4

(c) (5) (5) 2021 Alzobaidi et al. This work is published and licensed by Dove Medical Press Limited. The full terms of this license are available at https://www.dovepress.com/terms. C. ${ }_{\mathrm{BY}} \mathrm{NC}$ php and incorporate the Creative Commons Attribution - Non Commercial (unported, v3.0) License (http://creativecommons.org/licenses/by-nc/3.0/). By accessing the work you hereby accept the Terms. Non-commercial uses of the work are permitted without any further permission from Dove Medical Press Limited, provided the work is properly attributed. For permission for commercial use of this work, please see paragraphs 4.2 and 5 of our Terms (https://www.dovepress.com/terms.php). 
role of common medicinal plants, which are widely used in various traditional systems of medicine as potential preventative or treatment strategies against dementia.

\section{Pathogenesis of Dementia}

Substance abuse, subdural hematoma, intracranial tumors, neuro-infection, amyotrophic lateral sclerosis, and other neurodegenerative disorders are common causes of vascular dementias. ${ }^{4,5} \mathrm{AD}$ is the most dominant form of dementia, characterized by accumulation of beta-amyloid (amyloid plaques) and progressive microtubule disintegration, leading to synaptic loss, dysfunctional communication and neuronal cell apoptosis. Moreover, the $\beta$-amyloid plaques (insoluble proteins) accumulate between the neurons and interact with cell membranes, which trigger the oxidative stress and free calcium levels, and eventually lead to neuronal cell death. Pesticides, air pollutants and industrial toxic chemicals that easily penetrate blood-brain barriers can induce oxidative stress, neuronal damage and increase the progression of dementia. ${ }^{6,7}$ Autosomal genetic mutation in the central nervous system (CNS) is an important inherent factor associated with the early onset of $\mathrm{AD} .^{8}$ In the absence of definitive and effective treatment for dementia, lifestyle modification, phytopharmaceuticals, physical exercise, and practicing cognitive and social activities are considered effective means for disease treatment and prevention. ${ }^{9}$ Some drugs approved by the FDA are currently used for dementia management, but they were reported to have several adverse effects. Therefore, it is necessary to explore safer strategies from evidence-based medicine that can control dementia (Figure 1).

\section{Medicinal Plants and Bioactive Compounds: An Alternative Therapeutic Strategy for Dementia Treatment}

Aging or cognitive diseases are characterized by amyloid protein deposition and cholinergic neurotransmission deficits in the brain. Unfortunately, currently available dementia treatments, such as choline esterase inhibitors, N-methyl-D-aspartate (NMDA) antagonists (memantine), and calcium channel blockers, have short-term efficacy, and only relieve symptoms rather than targeting the main underlying pathogenesis. ${ }^{10}$ Memantine is a relatively weak NMDA receptor antagonist, approved for AD by the FDA in 2003, given to patients with moderate to severe cognitive deficits, and is known to prevent neuronal damage and synaptic loss caused by upregulation of NMDA receptors. ${ }^{11}$ As conventional therapies have many side effects and fail to improve cognitive decline, natural products and non-pharmacological interventions appear to be promising and safer alternative approaches with a beneficial impact on cognitive behaviors, thus they
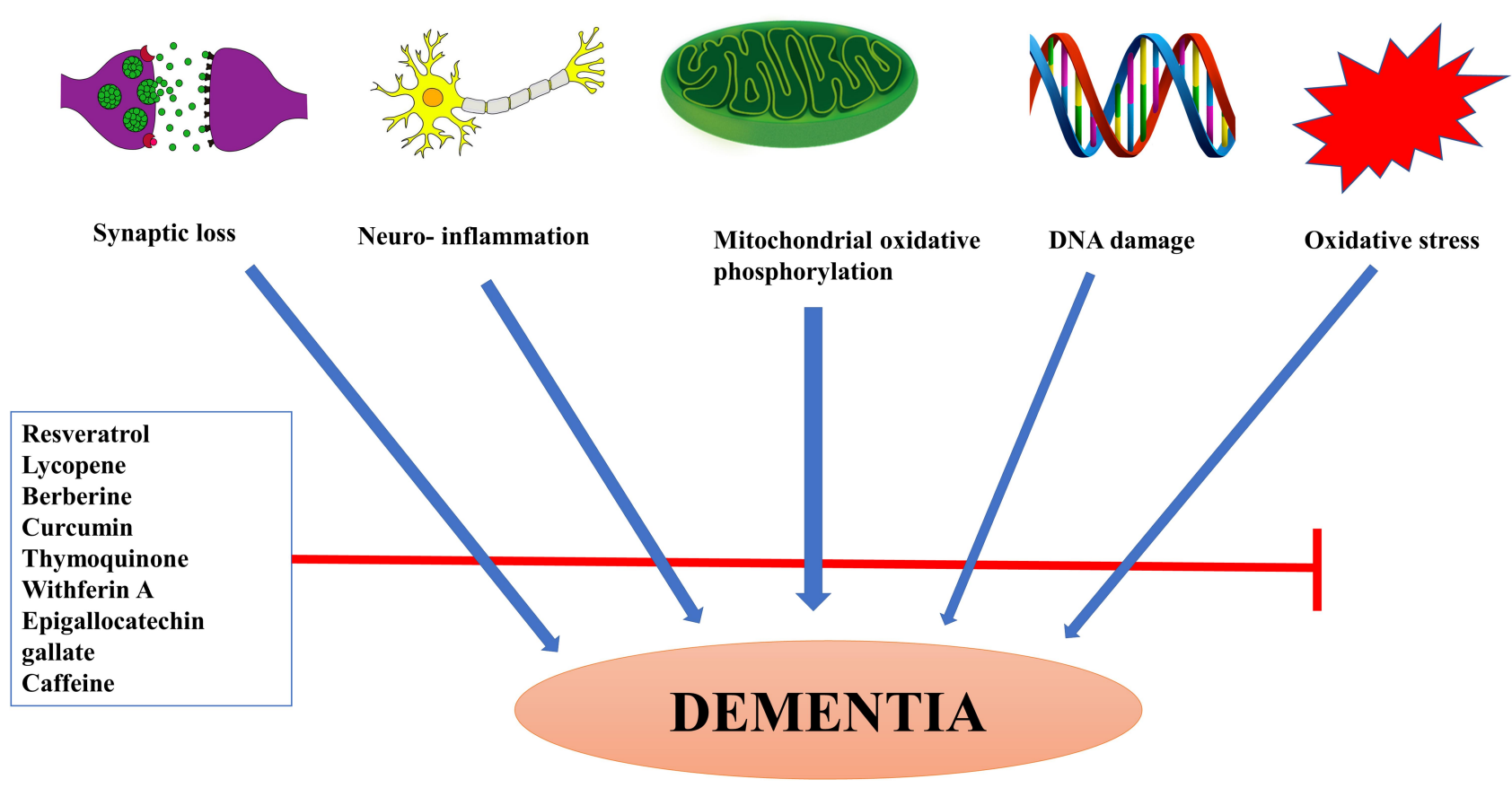

Figure I Illustrative diagram showing the potential mechanisms of bioactive compounds against dementia. 
should be central strategies in the treatment of memory impairment.

\section{Ginkgo biloba (Gb) L}

Ginkgo biloba $(\mathrm{Gb})$ is one of the most distinctive plants of the Ginkgoaceae family. Gb possesses a large genome, and it has high resistance to plant pathogens and other environmental factors, such as intense sunlight, temperature, high soil salinity, and so on. ${ }^{12} \mathrm{~Gb}$ has been widely used for the treatment of various neurovascular disorders, such as vertigo, tinnitus, venous insufficiency, fatigue and agerelated physical and cognitive disorders. ${ }^{13}$ EGb761, is a standard $\mathrm{Gb}$ extract, contains a mixture of flavonoids (primarily quercetin, kaempferol, and isorhamnetin) and terpenoids (2.8-3.4\% ginkgolides $\mathrm{A}, \mathrm{B}$, and $\mathrm{C}$, and $2.6-3.2 \%$ bilobalide). It has been extensively studied as an effective treatment for memory impairment. Also, it has been reported as an effective therapy against a wide variety of CNS disorders, such as depression, anxiety, stroke, and cerebral insufficiency. ${ }^{14,15} \mathrm{~Gb}$ extract has potential therapeutic effects on ischemic brain injury, cognitive and neurological disorders by improving cerebral perfusion and inhibiting platelet-activating factors. Flavonoids and terpene lactones like ginkgolides and bilobalides are the most isolated phytoconstituents from $\mathrm{Gb}$ extract. A standardized $\mathrm{Gb}$ extracts effectively reduced tissue damage after brain ischemia, attenuated oxidative stress, and improved cognitive dysfunction in various experimental rat models of dementia and chronic stress. ${ }^{16-18}$ An in vitro study evaluated the antiplatelet activity of EGb761 and concluded that $\mathrm{Gb}$ extract has protective effects and functional integrity on cerebral microvascular endothelial cells. ${ }^{19}$ Cell line studies showed that $\mathrm{Gb}$ extract protected cultured brain cells against neurotoxicants like nitric oxide ${ }^{20}$ and cyanide. ${ }^{21}$ Oral or intraperitoneal administration of $10-100 \mathrm{mg} / \mathrm{kg}$ of $\mathrm{Gb}$ extract prevented neuronal damage caused by transient middle cerebral artery occlusion (MCAO) in rats. ${ }^{21,22}$ In one model of vascular dementia in gerbils, EGb761 significantly improved spatial learning and memory, protected the hippocampal CA1 neurons and increased SOD activity in plasma. ${ }^{23}$ Chronic administration of $\mathrm{Gb}$ leaf extract protected rats' brain against biochemical and degenerative changes induced by aluminum chloride through increasing endogenous antioxidant and inhibiting the formation of free radicals. ${ }^{24}$ Additionally, treatment with $\mathrm{Gb}$ extract has been found to display antioxidant and neuroprotective activities on the prefrontal cortex and dorsal hippocampus of middle-aged rats. The study showed that chronic treatment with $\mathrm{Gb}$ extract improved age-related memory impairment and increased the survival of cortical neurons. ${ }^{25}$ In a randomized, placebo-controlled clinical trial, the study findings showed that daily administration of $240 \mathrm{mg}$ of $\mathrm{Gb}$ extract was safe and effective in the treatment of patients with dementia. ${ }^{26}$ Furthermore, a meta-analysis study by Wang et al proved that $\mathrm{Gb}$ could be an effective treatment for vascular dementia. ${ }^{27}$ Another meta-analysis study explored the efficacy of EGb 761 in dementia patients treated with $120 \mathrm{mg}$ or $240 \mathrm{mg}$ per day when compared to placebo. The study results showed that EGb 761 was well tolerated in all trials and that $240 \mathrm{mg}$ of EGb 761 was more effective in improving cognition. ${ }^{28}$ In contrast, the findings of a randomized, controlled trial demonstrated that $120 \mathrm{mg}$ of $\mathrm{Gb}$ extract twice a day is not effective in reducing either the incidence rate of dementia or $\mathrm{AD}$ in elderly individuals aged $\geq 75$ years with normal cognition or those with mild cognitive impairment (MCI). ${ }^{29}$

G. biloba has a high cerebral bioavailability, a single dose of $E G b 761{ }^{\circledR}(90 \mathrm{mg} / \mathrm{kg})$ reaches its peak concentration after 1 hour and remains at measurable levels for 6 hours in rats' brain. ${ }^{30}$ Despite the safety and efficacy data of $\mathrm{Gb}$ in improving cognition, the co-administration of $\mathrm{Gb}$ with antipsychotic drugs like risperidone, phenytoin, or trazodone has been resulted in serious neurological side effects. ${ }^{31}$ Additional animal studies and clinical trials are required to assess the safety aspect and the potential interaction with other drugs.

\section{Withania somnifera (Ashwagandha)}

Withania somnifera or Ashwagandha or Indian Ginseng (fam. Solanaceae) is a popular Ayurvedic medicinal plant known for its adaptogenic and antistress effects. Ashwagandha is an essential ingredient in Thai traditional medicine; it is used for enhancing memory and body functions. The roots of $W$. somnifera contain several phytoconstituents such as alkaloids, withanolides, sitoindosides and flavonoids. Among these compounds, withaferin $\mathrm{A}$ is a molecule of interest that has shown a neuroprotective effect in various human and animal studies. The immunomodulatory and antioxidant potentials of these bioactive candidates have been explored in an experimental model of acute stress. ${ }^{32}$ Some of the plausible mechanisms of action of $W$. somnifera against $A D$ are (i) blocking $\beta$-amyloid $(A \beta)$ production; (ii) inhibition of NF- $\mathrm{BB}$ pathway; (iii) reduction of neuronal death; (iv) 
modulation of synaptic transmission and restoring antioxidant enzymes. ${ }^{33}$ Kuboyama et al have evaluated the effect of withanoside IV on memory improvement and synaptic reconstruction in $A \beta_{25-35}$ induced injury on cultured rat cortical neurons. The study findings revealed that oral administration of withanoside IV (10 micromole/kg/day) markedly induced neurite outgrowth, restored memory defects, and protected mice from axonal, dendritic and synaptic loss. ${ }^{34}$ In a preliminary placebo-controlled trial, Chengappa et al have studied the cognitive impact of standardized $W$. somnifera extract against bipolar disease. The researchers observed that $W$. somnifera extract $(500 \mathrm{mg} /$ day) significantly enhanced the cognitive tests and improved auditory-verbal working memory. ${ }^{35}$

\section{Panax ginseng C.A. Meyer (Ginseng)}

Ginseng is a slow-growing perennial herb (Family of Araliaceae; a genus of Panax), widely cultivated in northeastern China. In the last decade, many experimental studies have shown that this plant has a key function in preventing neurodegeneration and improving learning and memory deficits. ${ }^{36}$ Ginseng is an adaptogen, protects against various biological stressors. Ginsenosides, the most valuable active constituents in Panax ginseng roots, are known to have a wide range of pharmacological activities including anti-inflammatory, antioxidant, immunomodulatory, anti-cancer, anti-aging, and adaptogenic activities. Zhang et al studied the neuroprotective potential of ginsenoside $\mathrm{Rg} 2$ on memory impairment in a vascular dementia (VD) in a rat model of cerebral ischemic reperfusion. The study results indicated that a significant improvement in cognitive abilities and neurological responses in the ginsenoside $\mathrm{Rg} 2$ group relative to the disease control group. ${ }^{37} \mathrm{~A}$ significant reduction in $\mathrm{A} \beta_{40}$ and $\mathrm{A} \beta_{42}$ levels in the brains of transgenic mice and cultured neurons was demonstrated after treatment with ginsenoside $\operatorname{Rg} 3{ }^{38}$ Ginsenoside Rg5 has been tested and found to modulate cognitive dysfunction, neuroinflammation, and increased cholinergic activity in streptozotocin (STZ)-induced memory impairment in rats. ${ }^{39}$ Hur et al patented a pharmaceutical composition containing ginsenoside $\operatorname{Rg} 18$, it has neuroprotective activity against $A \beta-$ induced nerve cell death during brain inflammation. ${ }^{40}$ This invention produced a significant improvement of memory and learning skills using a model of $A \beta$ peptide to induce dementia. ${ }^{40}$ Ginsenoside $\operatorname{Rg} 1$ modulates the neurotransmission and enhances glutamate release in the CNS through a calcium/calmodulin-dependent protein kinase II-dependent signaling pathway. ${ }^{41}$ In a randomized controlled trial, recruited 61 AD patients, Mini-Mental State Examination (MMSE) and
Alzheimer's Disease Assessment Scale-Cognitive Subscale (ADAS-Cog) tests were used to assess the changes in cognitive and functional performance after chronic oral administration of Korean red ginseng (KRG) as an adjuvant treatment for dementia. The study results demonstrated that the ADAS and Clinical Dementia Rating Scale (CDR) were improved markedly after 24 weeks in the high-dose ( $9 \mathrm{~g}$ /day) KRG treated patients relative to those in the control group. ${ }^{42}$ Briefly, the active constituents of Panax ginseng play a crucial role in the regulation of amyloid- $\beta$ synthesis, acetylcholine signaling and neuro-inflammatory response. Thus, they could be potential candidates in the treatment of dementia and AD.

\section{Curcuma longa (Turmeric)}

Curcuma longa $\mathrm{L}$. is a tuberous herbaceous perennial plant with yellow flowers and wide leaves, belongs to the Zingiberaceae family, and grows in the tropical climate. Curcumin (diferuloylmethane) and curcuminoid analogs such as demethoxycurcumin and bisdemethoxycurcumin are the main bioactive components in the rhizome of Curcuma longa, and commonly used as natural coloring agents in food. In traditional Indian medicine, turmeric is widely used for the treatment of many pathological conditions, such as asthma, epilepsy, gallstone and diabetic. ${ }^{43}$ As previously described, neuroinflammation is one of the key causes of cognitive decline. Significant evidence from preclinical and clinical studies elucidated the key role of curcumin in attenuating the neuroinflammatory cytokines, such as monocyte chemoattractant protein 1 (MCP-), TNF- $\alpha$, IL-6 and TGF- $\beta .{ }^{44}$ A cell line study conducted by Park et al to assess the neuroprotective mechanisms of curcumin against $A \beta_{25-35}$ induced neurotoxicity in PC12 cells. The study findings have shown that curcumin exposure inhibited hyperphosphorylation of microtubule-associated tau proteins, reduced oxidative stress and intracellular calcium influx. ${ }^{45}$ Fluorescence and confocal microscopy were used to measure the $A \beta$ uptake by the macrophages of $\mathrm{AD}$ patients and control individuals. The results showed a significant increase of $A \beta$ uptake by the macrophages of $\mathrm{AD}$ patients compared to curcuminoids-treated and control groups. ${ }^{46}$ Curcumin has been found to enhance glutathione expression, antioxidant enzyme and heme oxygenase in dementia and $\mathrm{AD}$ patients. ${ }^{47}$ Agrawal et al studied the effect of curcumin on memory functions, brain insulin receptors (IRs), and acetylcholinesterase (AChE) activity in dementia model in rats. The researchers demonstrated that curcumin could significantly enhance cholinergic activity, attenuate oxidative damage and improve memory deficits in the (STZ)treated rats compared to controls. ${ }^{48}$ Ganguli et al have noticed 
lower $\mathrm{AD}$ incidence in the Indian population consuming a curcumin-rich diet compared to the US population. ${ }^{49}$ This neuroprotective potential was likely due to attenuation of oxidative stress and reduction of $A \beta$ deposition, which are the main causes of mitochondrial damage in the brain. Due to the poor oral bioavailability of curcumin, 2000 or $4000 \mathrm{mg} /$ day orally administered curcumin C3 complex (70-80\% curcumin) has shown a non-significant difference in the clinical efficacy between treatment groups. ${ }^{50}$

\section{Glycyrrhiza Genus}

Glycyrrhiza or liquorice is a perennial herb growing in the Mediterranean region, Asia, Southern Russia, and Iran. Glycyrrhiza is derived from ancient Greek, glykys means "sweet," and rhiza is "root. ${ }^{51}$ Glycyrrhizin is the main active component in liquorice, commonly used as a natural sweetener. In Ayurvedic and Unani medicine, liquorice is extensively used for various medical conditions, such as inflammation of respiratory airways and gastrointestinal tract disorders. Glycyrrhizic acid (GA), a triterpenoid saponin glycoside, has demonstrated its anti-inflammatory and neuroprotective effects in many experimental studies. Isoflavonoid derivatives, including glabrone, lico-isoflavone A and B, glabridine and galbrene, are also essential bio-active components isolated from liquorice extract. Liquiritigenin from Glycyrrhizae radix is a selective estrogen receptor- $\beta$ (ER $\beta)$ agonist, these receptors are distributed in the brain centers of learning and memory. ${ }^{52}$ Liquiritigenin has shown a good cerebral bioavailability with neuroprotective and antiinflammatory effects on $\mathrm{A} \beta_{25-35}$-induced neurotoxicity on rat hippocampal neurons. ${ }^{53}$ The neuroprotective effects of glycyrrhizin against neurotoxin 1-methyl-4-phenylpyridinium $\left(\mathrm{MPP}^{+}\right)$have been tested by Soo et al They demonstrated that glycyrrhizin has neuroprotective potential via prevention of mitochondrial damage, attenuation of oxidative stress, and restoration of glutathione depletion in differentiated PC12 cells. ${ }^{54}$ Isoliquiritigenin is another component identified in Glycyrrhiza species that can suppress the caspase-3 proapoptotic activity, and produce potential effectiveness against dementia similar to memantine. ${ }^{55}$

\section{Tea (Camellia sinensis)}

Worldwide, green tea, black tea, and oolong tea are popular stimulant drinks. In traditional Indian and Chinese systems of medicine, green tea is also used for the treatment of obesity, diabetes mellitus, and neuroinflammation. ${ }^{56}$ Here, we searched evidence from animal and human studies showing the crucial role of green tea- related compounds on cognitive functions and memory impairment. (-)-epigallocatechin-3-O-gallate (EGCG), is a natural compound contained in green tea extract has antiatherogenic and anti-inflammatory properties, and plays a key role in the prevention and treatment of neurodegenerative diseases. ${ }^{57}$ In Wistar rat model of dementia, $10 \mathrm{mg} /$ $\mathrm{kg} /$ day oral administration of EGCG for 4 weeks significantly reversed the cognitive deficit, reduced oxidative and nitrosative stress, and modulated AChE activity in STZ treated rats. ${ }^{58}$ Lee et al conducted a preclinical study on ICR mice to investigate the effect of EGCG on the systemic neuroinflammation and memory impairment. The study results showed that chronic oral administration of 1.5 and $3 \mathrm{mg} / \mathrm{kg}$ EGCG could inhibit lipopolysaccharide (LPS) induced cytokine release and amyloidogenesis, as well as prevent memory impairment, apoptotic neuronal cell death, and microglia activation. ${ }^{59}$

A prospective cohort study by Tomato et al assessed the cognitive-enhancing action of green tea among Japanese dementia patients aged $\geq 65$ years. The results have shown that more frequent intake of green tea could reduce dementia's incidence rate by $8.7 \%$ over 5.7 years of intake. ${ }^{60}$ L-theanine extracted from the leaves of green tea could protect memory deficits and hippocampal cell death by attenuating the neuronal oxidative damage and blocking $\mathrm{NF}-\kappa \mathrm{B}$ signaling pathway induced by $\mathrm{A} \beta_{42} .{ }^{61}$ Several findings from animal and human studies have demonstrated the neuroprotective potential of tea polyphenols, catechins and epicatechin, in improving cognitive decline and neuronal signaling. The potential mechanisms behind that are due to improving the endogenous antioxidant activities, regulation of apoptosis, reduction of $A \beta$ synthesis, and modulation of mitochondrial function and neural growth factors. ${ }^{62-64}$

\section{Brahmi (Bacopa monnieri)}

Bacopa monnieri (L.) also known as Brahmi, belongs to Scrophulariaceae family, it is a creeping, succulent, herb cultivated in the wetlands of the Indian subcontinent. ${ }^{65}$ Brahmi herbs have long been used in Indian Ayurvedic medicine to improve cognitive deficits related to brain aging. It has been demonstrated that Brahmi extract contains bacoside A, which has anti-inflammatory, analgesic, antistress, and antiepileptic actions. ${ }^{66}$ The bacoside metabolites of Brahmi can cross the BBB easily and improve cognition by increasing blood flow, not necessarily due to direct interactions with neural cells. Holcomb et al evaluated the effect of the Brahmi extract on amyloid $\beta$-induced AD in PSAPP mice. The study findings revealed that Brahmi extract is 
able to reduce amyloid plaque in mice cortex, and reverse Y-maze performance and open field hyperlocomotion behavior. ${ }^{67}$ Another study by Limpeanchob et al evaluated the protective effect of Brahmi on $A \beta$ - induced cell death in primary cortical neurons. The study confirmed that the neuroprotective effect is being due to the suppression of neuronal oxidative stress and enhancing cholinergic activity. ${ }^{68}$ Khan et al found that oral administration of Brahmi extract at $30 \mathrm{mg} / \mathrm{kg}$ for 14 days significantly improved memory and learning capability, and ameliorated the morphological changes due to oxidative damage induced by intracerebroventricular-streptozotocin (ICV-STZ) in the brain tissue of rats. This neuroprotective effect of Brahmi was attributable to the upregulated expression of hippocampal antioxidant enzymes. ${ }^{69}$ In a mouse model of trimethyltin (TMT)induced neurodegeneration and cognition dysfunction, administration of $50 \mathrm{mg} / \mathrm{kg} / \mathrm{day}$ of Brahmi extract significantly protected hippocampal neurons, enhanced neurogenesis, and improved cognitive performance in mice. ${ }^{70}$ Uabundit et al explored beneficial cognitive effects of Brahmi extract against ethyl choline aziridinium ion mediated cognitive decline and neurodegenerative in rats. They observed a decline in both the number and density of cholinergic neurons and improvement in spatial learning and memory. ${ }^{71}$ Bacoside treatment attenuated neurotoxicants (scopolamine, sodium nitrite, and platelet-activating factor antagonist)-induced amnesia, increased cholinergic activity, and reduced latency escape period in mice. ${ }^{72}$ Brahmi has positive effects on the treatment of attention deficit hyperactivity disorder (ADHD) in children and can improve cognitive functions in stroke and epileptic patients. ${ }^{73}$ Among the plausible mechanisms behind the neuroprotective effect of Brahmi are increasing glutathione expression and enhancing cerebral blood supply. ${ }^{72,74}$ Oral administration $300 \mathrm{mg}$ /day of standardized Brahmi extract in healthy elderly participants for 12 weeks significantly enhanced the cognitive tasks, Rey Auditory Verbal Learning Test (AVLT), Stroop test, and depression scores, confirming its safety and memoryenhancing effects. ${ }^{75}$ A randomized placebo-controlled trial has been conducted in India and enrolled 60 medical students to assess the impact of Bacopa monnieri on improving cognition among medical students. $150 \mathrm{mg}$ of standardized Brahmi extract $\left(\right.$ Bacognize $^{\circledR}$ ) twice daily for six weeks substantially improved auditory and visual neuropsychological tests and increased serum calcium compared to the control group. ${ }^{76}$ A study performed by Thakkar et al to enhance the poor solubility of Bacognize ${ }^{\circledR}$. Inclusion complex containing $16 \%$ bacosides and $\beta$-cyclodextrin at a molar ratio of $1: 4$ by co-precipitation method improved solubility and stability of Bacognize ${ }^{\circledR}$ by three times. ${ }^{77}$ Poor learning and ADHD are very common childhood disorders in the Western world. Administration of $10 \mathrm{~g}$ Brahmi to 40 rural Indian school children aged 6-8 years for 3 months significantly enhanced memory and response performance. ${ }^{78}$ Meta-analyses of randomized, double-blind, controlled trials demonstrated the beneficial effects of Brahmi on cognitive performance, particularly attention speed. ${ }^{79}$ In contrast, a study reported that supplementation of Brahmi extract and multiple micronutrients twice daily for 4 months did not show a significant impact in improving short-term memory in Indian school children. ${ }^{80}$ Despite the safety of Brahmi in animal studies and human trials, no studies regarding its safety in pregnancy, so it should not be used. ${ }^{81,82}$

\section{Nigella sativa}

Nigella sativa is a small black seed that belongs to the Ranunculaceae family, native to Southern Europe, North Africa, and Asia Minor, and it is also cultivated in Pakistan and India. N. sativa has long been used in traditional medicine as astringent, diuretic, anthelmintic, and for the treatment of intermittent fever and skin disease. ${ }^{83}$ Moreover, the therapeutic value of N. sativa was mentioned in many chapters of the Prophetic medicine book. $N$. sativa contains a variety of constituents, including proteins, alkaloid, alpha-hederin, saponin, vitamins, minerals, volatile and fixed oils. Unsaturated fatty acids represent up to $26.6 \%$ to $38 \%$ of the total oil content. ${ }^{84}$ Thymoquinone is the molecule of interest attributed to the pharmacological activities of the N. sativa. ${ }^{85}$ Thymol and carvacrol attenuated the disruption of cholinergic function and memory deficits induced by $\mathrm{A} \beta$ - and scopolamine in rats. ${ }^{86}$ Emerging evidence confirms that flavonoids of N.sativa are able to modulate specific changes in hippocampal protein expression involved in the learning and memory process. ${ }^{87} \mathrm{~A}$ preclinical study was conducted by Hosseini et al to explore the protective mechanism of $N$. sativa hydroalcoholic extract in scopolamine-induced spatial memory impairment in male Wistar rats. The study results explored that N. Sativa purified oils enhanced memory performance, cholinergic activity, and reduced oxidative stress in rat brain tissues. ${ }^{88}$ Similarly, a study performed by Khan et al to evaluate the neuroprotective effect of thymoquinone (3mg/kg body weight) for 15 days against streptozotocininduced cognitive impairment in rats. The study findings revealed that thymoquinone reduced the levels of 
oxidative stress markers, and significantly decreased the latency time and the path length in the Morris Water Maze (MWM) test. ${ }^{89}$ Thymoquinone $(1.642 \mathrm{mg}$ ) ameliorated $A \beta_{1-42}$ induced neurotoxicity in rat hippocampal and cortical cultured neurons, and prevented the mitochondrial membrane potential depolarization. ${ }^{90}$ A clinical study by Bin Sayeed et al has investigated the effect of $N$. sativa on anxiety and cognitive decline. The study findings reported that oral intake of $N$. sativa $500 \mathrm{mg} /$ day over four weeks as a nutritional supplement was found to stabilize mood, decrease anxiety and modulate cognition on adolescent human male participants. ${ }^{91}$ Taken together, these collective evidences put thymoquinone in the top list of phytopharmaceuticals as a promising candidate for the treatment of dementia and AD.

\section{Phytochemicals}

Resveratrol (3,5,4'- trihydroxystilbene) belongs to a family of polyphenolic compounds known as stilbenes. Peanuts, pistachios, berries, and grapes are essential sources of resveratrol. $^{92}$ The trans-isomer of resveratrol in the skin of most grape species is more effective and more stable than Cis-isomer. Resveratrol has been shown to exhibit anti-cancer, anti-inflammatory, anti-aging, cardioprotective and anti-oxidant properties. ${ }^{93,94}$ Also, it has anti-amyloidogenic effects and could inhibit the formation and extension of neurotoxic $A \beta$ fibrils. ${ }^{95}$ A cell line study by Vingtdeux et al studied the potential effect of resveratrol in AD. The investigators observed that resveratrol was able to inhibit the extracellular $A \beta$ accumulation by facilitating its proteolytic clearance in neuronal cells, and activation of AMP-activated protein kinase in the cerebral cortex of transgenic mice. ${ }^{96}$ In order to enhance the cerebral bioavailability of resveratrol, the development of novel formulations for brain targeting is highly recommended.

Lycopene is an aliphatic hydrocarbon carotenoid extracted from tomatoes, watermelons, and papayas. It is a strong anti-oxidant, anti-inflammatory, and antiproliferative agent. Lycopene is well known for its beneficial effects against solid tumors and non-alcoholic fatty liver. $^{97,98}$ Improvement of prostate cancer after a long period of tomato sauce consumption and the prospective association between reduction of plasma glucose level and chronic lycopene intake have been reported in independent clinical studies. ${ }^{99,100}$ The underlying mechanism of lycopene in the treatment of memory deficits is not fully understood. Long-term lycopene intake has been found to inhibit the oxidative stress and reduce infarct volume and neuronal apoptosis in cerebral ischemia/reperfusion in high-fat diet-induced cognitive impairment in rats. ${ }^{101}$ $50 \mathrm{mg} / \mathrm{kg}$ of lycopene supplementation for 60 days significantly reduced the levels of inflammatory cytokines, prevented neuronal degeneration and nucleus shrinkage in the brains of aged CD-1 mice. ${ }^{101}$ Zhu et al conducted a study on a rat model of bilateral carotid artery occlusion induced VD to evaluate the protective effect of lycopene on memory impairment. The study results indicated that chronic administration of lycopene could effectively inhibit oxidative stress and reduce the expression of neuronrestrictive silencer factor $(N R S F)$ in rats' brains. ${ }^{102}$

Berberine is an isoquinoline alkaloid extracted from barberry, it has wide medicinal uses in the treatment of bacterial diarrhea, hypercholesterolemia, type 2 diabetes, cardiac disease, and cancer. ${ }^{103}$ Despite many experimental studies elucidating the neuroprotective effects of berberine, its definite mechanism of enhancing memory functions is not fully understood. An in vitro study by Asai et al explored that $10 \mu \mathrm{mol} \mathrm{\textrm {L } ^ { - 1 }}$ berberine could reduce amyloid $\beta$ levels to $30 \%$ via modulation of the amyloid precursor protein (APP) pathway in human neuroglioma H4 cells. ${ }^{104}$ Another in vitro study investigated the potential effect of berberine on $A \beta$-induced mitochondrial dysfunction in primary cultured hippocampal neurons. The study findings confirmed that berberine may preserve mitochondrial membrane potential, improve mitochondrial motility and prevent synaptic loss. ${ }^{105}$

Caffeine is a naturally occurring CNS stimulant found in coffee, tea, and other plants. It has been used for medicinal purposes in many systems of traditional medicine for over thousands of years. Coffee is the main source of caffeine, and it contains phenolics and other bioactive compounds that may have either positive or negative effects on health. Different coffee preparations contain varying levels of caffeine, such as $0.6-3.3 \mathrm{mg} / \mathrm{mL}$ in espresso, $0.7-1.1 \mathrm{mg} / \mathrm{mL}$ in boiled or filtered coffee, and $0.2-0.6 \mathrm{mg} / \mathrm{mL}$ in instant coffee. ${ }^{106}$ Caffeine is absorbed from the gastrointestinal tract rapidly; $99 \%$ is absorbed in about 45 min after ingestion. ${ }^{107}$ Caffeine binds with A1 and $\mathrm{A} 2 \mathrm{~A}$ adenosine receptors. It has positive effects on attention, arousal, mood and vigilance. In high amounts, caffeine can induce anxiety, restlessness, insomnia and psychomotor agitation. ${ }^{108}$ Crude caffeine has higher levels of hydrophilic and lipophilic antioxidant activity than pure caffeine. Caffeine when given in high doses has been 
reported to inhibit phosphorylation of esterase enzyme which in turn leads to the induction of calcium release from the sarcoplasmic reticulum, thus activating protein kinase A. This cascade of signaling pathways is in the phosphorylation of enzymes involved in glucose and lipid metabolism. Caffeine intake minimizes the risk of cognitive impairment in neurological conditions, including sleep deprivation, alcohol consumption, diabetes, Parkinson's disease, and AD. ${ }^{109,110}$ Several in vitro and in vivo studies reported that caffeine exhibits neuroprotective effects as it protects cortical neurons against $A \beta$ toxicity as well as prevents $A \beta$-induced memory deficits in mice. ${ }^{111} \mathrm{~A}$ longterm study in mice has supported that as well, showing that caffeine intakes can prevent the memory decline related to age which is associated with changes in neurotrophic factor (BDNF). ${ }^{112}$ It has been reported that caffeine treatment at $40 \mathrm{mg} / \mathrm{kg}$ significantly enhances $A \beta$ clearance $(20 \%)$ in the brain endothelial cells of C57BL/ 6 mice. ${ }^{113}$ In another related study, it is found out that caffeine $(0.6 \mathrm{mg} / \mathrm{d})$ increases hippocampal mitochondrial respiration (25\%) and ATP levels (46\%) in the APPSw mice. Caffeine increases hippocampal mitochondrial membrane potential $(78 \%)$ and decreases ROS production $(100 \%)$ in Alzheimer's mice. ${ }^{114}$ Caffeine decreased the cholesterol-induced increase in $\mathrm{A} \beta$, phosphorylated tau, and oxidative stress levels in rabbits' hippocampus and reversed the cholesterol-induced decrease in adenosine A1 receptors (A1R) levels when given in the drinking water at 0.5 and $30 \mathrm{mg} /$ day. ${ }^{115}$ Many randomized controlled trials support the potential role of caffeine in improving cognition. A 21-year follow-up study ( 875 women and 534 men, age 50 years) concluded that moderate consumption (3-5 cups) of coffee substantially reduced the risk of AD (62-64\%) and dementia $(65-70 \%)$ later in life, compared with low coffee consumers (0-2 cups). ${ }^{116}$ The consumption of caffeine is linked to faster processing of new information and improved simple reaction time. ${ }^{117}$ In a large prospective cohort study of 2475 females over 65 years old with vascular diseases, the relation between habitual caffeine uses and long-term cognitive decline was examined over five years. As a result, coffee consumption was linked to a slower rate of cognitive decline, especially in women with stable diets. ${ }^{118}$ In another prospective study conducted by the Canadian Study of Health and Aging (CSHA) for five years, daily coffee consumption reduced the risk of AD by $31 \% .{ }^{119}$ However, at autopsy, patients who consumed more than $277.5 \mathrm{mg}$ of caffeine a day had a decreased probability of presenting AD-related lesions, or other ischemic lesions. ${ }^{120}$ Caffeine has been found to reduce the risk of developing $\mathrm{AD}$ in patients with apolipoprotein E (ApoE $\varepsilon 4)$ allele. ${ }^{121}$ In contrast, a recent study from the Honolulu-Asian Aging Study failed to establish a significant correlation between caffeine consumption and dementia risk. ${ }^{36}$ Similarly, a longitudinal study in the Netherlands reported that no significant correlation between caffeine intake and a reduced risk of cognitive decline. ${ }^{122}$

In addition to the aforementioned medicinal plants and bioactive candidates (Figure 2), several marketed herbal formulations are currently used for dementia treatment. Yukmijihwang-tang is a common herbal product in Korea, China and Japan used to enhance memory. It has been found to inhibit apoptosis by enhancing the expression of the neuron-specific proteins transthyretin and PEP19 in the brains of rats exposed to neurotoxicant. ${ }^{123}$ Another cognitive enhancer herbal formulation is a Chinese Naoweikang, containing Ginkgo biloba and Panax ginseng. It has been tested and found to modulate the cholinergic pathway against $A \beta_{1-40}$ induced neurotoxicity in the brain of Sprague Dawley rats. ${ }^{124}$ ESP-2, a standardized Korean combined extract of Angelica gigas, Saururus chinensis and Schizandra chinensis effectively inhibited AChE activity and reversed scopolamineinduced memory impairment in ICR mice. ${ }^{125}$

\section{Future Prospective}

Dementias and Alzheimer's disease are closely intertwined multifactorial diseases caused by a cascade of genetic and environmental risk factors developing over a period of time. The heterogeneous nature of factors causing the disease has made it very difficult to find the right treatment as one drug will not be sufficient to make a difference in all related dementias. Therefore, there has not been any substantial progress in the development of a successful line of dementia treatment. The reason behind the multiple failures of clinical trials of drugs targeting memory loss could be attributed to delay in the starting of therapies in the disease progression, ineffective drug doses, incorrect target of the treatment, and most importantly an incomplete understanding of the pathophysiology of memory loss, as well as the progression of neuro-degeneration.

It is the need of the hour to identify the underlying cause of the disease and to develop alternative approaches targeting multiple pathways of dementia and AD. Herbal drugs could be used as an alternative medicine for the treatment of neurodegenerative disorders and could also help in alleviating the sufferings of the patients. Herbal 

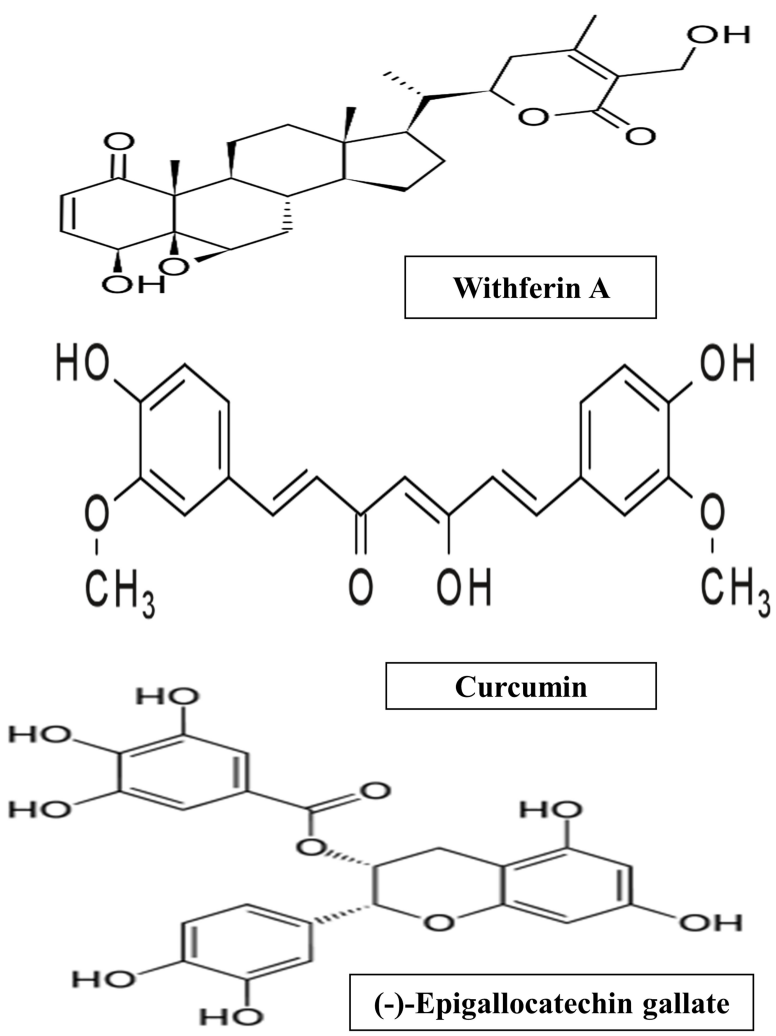

Figure 2 Chemical structure of bioactive molecules with potential anti-dementia activity.

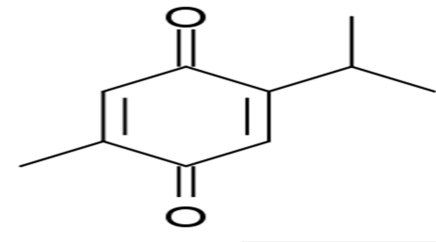

Thymoquinone<smiles>Cn1c(=O)c2c(ncn2C)n(C)c1=O</smiles>

Caffeine

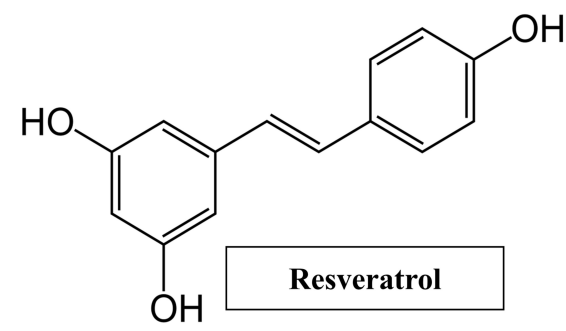

drugs are less toxic as compared to their synthetic counterparts, bioavailable, have multiple synergistic effects and enhance cognition. However, the variable constituents in medicinal plants and variable preparations based on genetic, cultural and environmental factors are the biggest impediment in the amalgamation of herbal medicines into modern medicines.

To ensure efficient and ethical care in dementia, psychoeducation, advanced planning for future care needs as well as appropriate pharmaceutical treatment along with environmental and behavioral techniques are instrumental. Several studies are ongoing in full swing for assessment of the benefits of an Alzheimer's vaccine (having component of an antigenic amyloid protein, amyloid enzyme inhibitors and nerve growth factor therapies). These approaches may prove to be promising, however, extensive research needs to be done. It becomes imperative to develop a standardized approach for treating patients individually with the help of detailed research which should focus on identifying the active ingredients of plants and investigating their mechanism of action.

\section{Conclusions}

Herein, we reviewed the most medicinal plants which are being used in various traditional systems of medicine, and explain the related mechanisms and effects against dementia. All these collective evidences gathered from clinical trials and animal studies support the treasured value of medicinal plants as an alternative strategy for the prevention or treatment of dementia. Herbal plants and phytoactive compounds are superior in terms of safety when compared with synthetic drugs such as donepezil, and considered as promising alternative strategies for improving memory deficits. Animal models of dementia are not sufficient to understand the plausible explanation of these herbal candidates, thus further clinical studies with a larger sample size are required for developing evidencebased medicines for the treatment of dementia and AD.

\section{Funding}

There is no funding to report.

\section{Disclosure}

The authors have declared no conflicts of interest for this work. 


\section{References}

1. Chang D, Liu J, Bilinski K, et al. Herbal medicine for the treatment of vascular dementia: an overview of scientific evidence. Evid Based Compl Altern Med. 2016;2016:1-15. doi:10.1155/ 2016/7293626

2. Tewari D, Stankiewicz AM, Mocan A, Sah AN. Ethnopharmacological approaches for dementia therapy and significance of natural products and herbal drugs. Front Aging Neurosci. 2018;10(3):1-24. doi:10.3389/fnagi.2018.00003

3. Rossor MN, Fox NC, Mummery CJ, Schott JM, Warren JD. The diagnosis of young-onset dementia. Lancet Neurol. 2010;9 (8):793-806. doi:10.1016/S1474-4422(10)70159-9

4. Tripathi M, Vibha D. Reversible dementias. Indian J Psychiatry. 2009;51(Supp11):S52.

5. Iadecola C. The pathobiology of vascular dementia. Neuron. 2013;80(4):844-866.

6. Rivas-Arancibia S, Hernández-Zimbrón LF, Rodríguez-Martínez E, Borgonio-Pérez G, Velumani V, Durán-Bedolla J. Chronic exposure to low doses of ozone produces a state of oxidative stress and blood-brain barrier damage in the hippocampus of rat. Adv Biosci Biotechnol. 2013;04(11):24-29. doi:10.4236/ abb.2013.411A2004

7. Yan D, Zhang Y, Liu L, Yan H. Pesticide exposure and risk of alzheimer's disease: a systematic review and meta-analysis. Sci Rep. 2016;6(1):1-9. doi:10.1038/s41598-016-0001-8

8. Giri M, Zhang M, Lü Y. Genes associated with alzheimer's disease: an overview and current status. Clin Interv Aging. 2016;11:665-681. doi:10.2147/CIA.S105769

9. Mecocci P, Tinarelli C, Schulz RJ, Polidori MC. Nutraceuticals in cognitive impairment and alzheimer's disease. Front Pharmacol. 2014;5 JUN(June):1-12.

10. Van Marum RJ. Update on the use of memantine in alzheimer's disease. Neuropsychiatr Dis Treat. 2009;5(1):237-247. doi:10.2147/NDT.S4048

11. Danysz W, Parsons CG, Möbius H, Stöffler A, Quack G. Neuroprotective and symptomatological action of memantine relevant for alzheimer's disease - a unified glutamatergic hypothesis on the mechanism of action. Neurotox Res. 2000;2(2-3):85-97. doi:10.1007/BF03033787

12. Guan R, Zhao Y, Zhang H, et al. Draft genome of the living fossil Ginkgo biloba. Gigascience. 2016;5(1):49. doi:10.1186/s13742016-0154-1

13. Sun ZK, Yang HQ, Chen SD. Traditional Chinese medicine: a promising candidate for the treatment of alzheimer's disease. Transl Neurodegener. 2013;2(1):1-7. doi:10.1186/2047-9158-2-6

14. Holstein N. Ginkgo special extract EGb 761 in tinnitus therapy. An overview of results of completed clinical trials. Fortschr Med Orig. 2001;118(4):157-164.

15. Schneider B. Ginkgo biloba extract in peripheral arterial diseases. Meta-analysis of controlled clinical studies. Arzneimittelforschung. 1992;42(4):428-436.

16. Lee EJ, Chen HY, Wu TS, Chen TY, Ayoub IA, Maynard KI. Acute administration of Ginkgo biloba extract (EGb 761) affords neuroprotection against permanent and transient focal cerebral ischemia in Sprague-Dawley rats. J Neurosci Res. 2002;68 (5):636-645. doi:10.1002/jnr.10251

17. Bridi R, Crossetti FP, Steffen VM, Henriques AT. The antioxidant activity of standardized extract of Ginkgo biloba (EGb 761) in rats. Phytother Res. 2001;15(5):449-451. doi:10.1002/ptr.814

18. Domoráková I, Burda J, Mechírová E, Feriková M. Mapping of rat hippocampal neurons with NeuN after ischemia/reperfusion and Ginkgo biloba extract (EGb 761) pretreatment. Cell Mol Neurobiol. 2006;26(7-8):1193-1204. doi:10.1007/s10571-0069080-6
19. Kim JM, Ryou SH, Kang YH. Effect of Ginkgo biloba leaf powder and extract on plasma and liver lipids, platelet aggregation and erythrocyte $\mathrm{Na}+$ efflux in rats fed hypercholesterolemic diet. FASEB J. 2011;25:S1.

20. Bastianetto S, Zheng WH, Quirion R. The Ginkgo biloba extract (EGb 761) protects and rescues hippocampal cells against nitric oxide-induced toxicity: involvement of its flavonoid constituents and protein kinase C. J Neurochem. 2000;74(6):2268-2277. doi:10.1046/j.1471-4159.2000.0742268.x

21. Krieglstein J, Ausmeier F, El-Abhar H, et al. Neuroprotective effects of Ginkgo biloba constituents. Eur J Pharm Sci. 1995;3 (1):39-48. doi:10.1016/0928-0987(94)00073-9

22. Zhang WR, Hayashi T, Kitagawa H, et al. Protective effect of Ginkgo extract on rat brain with transient middle cerebral artery occlusion. Neurol Res. 2000;22(5):517-521. doi:10.1080/ 01616412.2000.11740713

23. Rocher MN, Carré D, Spinnewyn B, et al. Long-term treatment with standardized Ginkgo biloba extract (EGb 761) attenuates cognitive deficits and hippocampal neuron loss in a gerbil model of vascular dementia. Fitoterapia. 2011;82(7):1075-1080.

24. Mohamed NES, Abd El-Moneim AE. Ginkgo biloba extract alleviates oxidative stress and some neurotransmitters changes induced by aluminum chloride in rats. Nutrition. 2017;35(93-9). doi:10.1016/j.nut.2016.10.012

25. Ribeiro ML, Moreira LM, Arçari DP, et al. Protective effects of chronic treatment with a standardized extract of Ginkgo biloba L. in the prefrontal cortex and dorsal hippocampus of middle-aged rats. Behav Brain Res. 2016;313:144-150. doi:10.1016/j.bbr.2016.06.029

26. Herrschaft H, Nacu A, Likhachev S, Sholomov I, Hoerr R, Schlaefke S. Ginkgo biloba extract EGb $761{ }^{\circledR}$ in dementia with neuropsychiatric features: a randomised, placebo-controlled trial to confirm the efficacy and safety of a daily dose of $240 \mathrm{mg}$. $J \quad$ Psychiatr Res. 2012;46(6):716-723. doi:10.1016/j. jpsychires.2012.03.003

27. Wang M, Peng H, Peng Z, et al. Efficacy and safety of ginkgo preparation in patients with vascular dementia: a protocol for systematic review and meta-analysis. Medicine. 2020;99(37): e22209. doi:10.1097/MD.0000000000022209

28. Gauthier S, Schlaefke S. Efficacy and tolerability of Ginkgo biloba extract EGb $761^{\circledR}$ in dementia: a systematic review and meta-analysis of randomized placebo-controlled trials. Clin Interv Aging. 2014;9:2065-2077. doi:10.2147/CIA.S72728

29. Williamson JD, Fitzpatrick AL, Kronmal RA, et al. Ginkgo biloba for prevention of dementia. JAMA. 2008;300 (19):2253-2262. doi:10.1001/jama.2008.683

30. Chen F, Li L, Xu F, et al. Systemic and cerebral exposure to and pharmacokinetics of flavonols and terpene lactones after dosing standardized Ginkgo biloba leaf extracts to rats via different routes of administration. Br J Pharmacol. 2013;170(2):440-457. doi:10.1111/bph.12285

31. Izzo AA. Interactions between herbs and conventional drugs: overview of the clinical data. Med Princ Pract. 2012;21 (5):404-428. doi:10.1159/000334488

32. Mishra LC, Singh BB, Dagenais S. Scientific basis for the therapeutic use of Withania somnifera (ashwagandha): a review. Altern Med Rev. 2000;5(4):334-346.

33. Farooqui AA, Farooqui T, Madan A, Ong JHJ, Ong WY. Ayurvedic medicine for the treatment of dementia: mechanistic aspects. Evid Based Compl Altern Med. 2018;2018:1-11. doi:10.1155/2018/2481076

34. Kuboyama T, Tohda C, Komatsu K. Withanoside IV and its active metabolite, sominone, attenuate $\mathrm{A} \beta(25-35)$-induced neurodegeneration. Eur J Neurosci. 2006;23(6):1417-1426. doi:10.1111/ j.1460-9568.2006.04664.x 
35. Chengappa KNR, Bowie CR, Schlicht PJ, Fleet D, Brar JS, Jindal R. Randomized placebo-controlled adjunctive study of an extract of Withania somnifera for cognitive dysfunction in bipolar disorder. J Clin Psychiatry. 2013;74(11):1076-1083. doi:10.4088/ JCP. $13 \mathrm{~m} 08413$

36. Kim KH, Lee D, Lee HL, Kim CE, Jung K, Kang KS. Beneficial effects of panax ginseng for the treatment and prevention of neurodegenerative diseases: past findings and future directions. J Ginseng Res. 2018;42(3):239-247. doi:10.1016/j. jgr.2017.03.011

37. Zhang G, Liu A, Zhou Y, San X, Jin T, Jin Y. Panax ginseng ginsenoside-Rg2 protects memory impairment via anti-apoptosis in a rat model with vascular dementia. J Ethnopharmacol. 2007;115(3):441-448. doi:10.1016/j.jep.2007.10.026

38. Chen F, Eckman EA, Eckman CB, Chen F, Eckman EA, Eckman CB. Reductions in levels of the alzheimer's amyloid $\beta$ peptide after oral administration of ginsenosides. FASEB J. 2006;20(8):1269-1271. doi:10.1096/fj.05-5530fje

39. Chu S, Gu J, Feng L, et al. Ginsenoside Rg5 improves cognitive dysfunction and beta-amyloid deposition in STZ-induced memory impaired rats via attenuating neuroinflammatory responses. Int Immunopharmacol. 2014;19(2):317-326. doi:10.1016/j. intimp.2014.01.018

40. Hur JY, Kim SS, Kim KT, et al., inventors; Korea Food Res Inst., assignee. $\operatorname{Rg} 18$ pharmaceutical composition for improving preventing or treating a degenerative disease comprising ginsenoside Rg18. Korean patent KR101771679 (B1). 2017 Aug 29.

41. Liu ZJ, Zhao M, Zhang Y, Xue JF, Chen NH. Ginsenoside Rg1 promotes glutamate release via a calcium/calmodulin-dependent protein kinase II-dependent signaling pathway. Brain Res. 2010;1333:1-8. doi:10.1016/j.brainres.2010.03.096

42. Heo JH, Lee ST, Chu K, et al. An open-label trial of Korean red ginseng as an adjuvant treatment for cognitive impairment in patients with alzheimer's disease. Eur J Neurol. 2008;15 (8):865-868. doi:10.1111/j.1468-1331.2008.02157.x

43. Brondino N, Re S, Boldrini A, et al. Curcumin as a therapeutic agent in dementia: a mini systematic review of human studies. $\mathrm{Sci}$ World J. 2014;2014.

44. Panahi Y, Hosseini MS, Khalili N, et al. Effects of curcumin on serum cytokine concentrations in subjects with metabolic syndrome: a post-hoc analysis of a randomized controlled trial. Biomed Pharmacother. 2016;82:578-582. doi:10.1016/j. biopha.2016.05.037

45. Park SY, Kim HS, Cho EK, et al. Curcumin protected PC12 cells against beta-amyloid-induced toxicity through the inhibition of oxidative damage and tau hyperphosphorylation. Food Chem Toxicol. 2008;46(8):2881-2887. doi:10.1016/j.fct.2008.05.030

46. Zhang L, Fiala M, Cashman J, et al. Curcuminoids enhance amyloid- $\beta$ uptake by macrophages of alzheimer's disease patients. J Alzheimers Dis. 2006;10(1):1-7. doi:10.3233/JAD-2006-10101

47. Molino S, Dossena M, Buonocore D, et al. Polyphenols in dementia: from molecular basis to clinical trials. Life Sci. 2016;161:69-77. doi:10.1016/j.lfs.2016.07.021

48. Agrawal R, Mishra B, Tyagi E, Nath C, Shukla R. Effect of curcumin on brain insulin receptors and memory functions in STZ (ICV) induced dementia model of rat. Pharmacol Res. 2010;61(3):247-252. doi:10.1016/j.phrs.2009.12.008

49. Ganguli M, Chandra V, Kamboh MI, et al. Apolipoprotein $\mathrm{E}$ polymorphism and alzheimer disease: the Indo-US cross-national dementia study. Arch Neurol. 2000;57 (6):824-830. doi:10.1001/archneur.57.6.824

50. Ringman JM, Frautschy SA, Teng E, et al. Oral curcumin for alzheimer's disease: tolerability and efficacy in a 24-week randomized, double blind, placebo-controlled study. Alzheimers Res Ther. 2012;4(5):43. doi:10.1186/alzrt146
51. Öztürk M, Altay V, Hakeem KR, Akçiçek E. Liquorice: From Botany to Phytochemistry. Springer; 2019.

52. Mersereau JE, Levy N, Staub RE, et al. Liquiritigenin is a plantderived highly selective estrogen receptor $\beta$ agonist. Mol Cell Endocrinol. 2008;283(1-2):49-57. doi:10.1016/j. mce.2007.11.020

53. Liu RT, Zou LB, Lü QJ. Liquiritigenin inhibits A $\beta 25-35$-induced neurotoxicity and secretion of A $\beta 1-40$ in rat hippocampal neurons. Acta Pharmacol Sin. 2009;30(7):899-906. doi:10.1038/ aps.2009.74

54. Soo BY, Sang EP, Chung SL. Protective effect of glycyrrhizin on 1-methyl-4-phenylpyridinium-induced mitochondrial damage and cell death in differentiated PC12 cells. J Pharmacol Exp Ther. 2007;321(2):816-822. doi:10.1124/jpet.107.119602

55. Danysz W, Parsons CG. The NMDA receptor antagonist memantine as a symptomatological and neuroprotective treatment for alzheimer's disease: preclinical evidence. Int $J$ Geriatr Psychiatry. 2003;18(S1):S23-S32. doi:10.1002/gps.938

56. Isemura M, Miyoshi N, Pervin M, Suzuki T, Unno K, Nakamura Y. Green tea catechins for well-being and therapy: prospects and opportunities. Bot Targets Ther. 2015;5:85-96. doi:10.2147/BTAT.S91784

57. Cascella M, Bimonte S, Muzio MR, Schiavone V, Cuomo A. The efficacy of epigallocatechin-3-gallate (green tea) in the treatment of alzheimer's disease: an overview of pre-clinical studies and translational perspectives in clinical practice. Infect Agent Cancer. 2017;12(1):1-7. doi:10.1186/s13027-017-0145-6

58. Biasibetti R, Tramontina AC, Costa AP, et al. Green tea (-) epigallocatechin-3-gallate reverses oxidative stress and reduces acetylcholinesterase activity in a streptozotocin-induced model of dementia. Behav Brain Res. 2013;236(1):186-193. doi:10.1016/j.bbr.2012.08.039

59. Lee YJ, Choi DY, Yun YP, Han SB, Oh KW, Hong JT. Epigallocatechin-3-gallate prevents systemic inflammation-induced memory deficiency and amyloidogenesis via its anti-neuroinflammatory properties. $J$ Nutr Biochem. 2013;24(1):298-310. doi:10.1016/j.jnutbio.2012.06.011

60. Tomata Y, Sugiyama K, Kaiho Y, et al. Green tea consumption and the risk of incident dementia in elderly Japanese: the Ohsaki Cohort 2006 Study. Am J Geriatr Psychiatry. 2016;24 (10):881-889. doi:10.1016/j.jagp.2016.07.009

61. Kim TI, Lee YK, Park SG, et al. 1-Theanine, an amino acid in green tea, attenuates $\beta$-amyloid-induced cognitive dysfunction and neurotoxicity: reduction in oxidative damage and inactivation of ERK/p38 kinase and NF-кB pathways. Free Radic Biol Med. 2009;47(11):1601-1610. freeradbiomed.2009.09.008 doi: $10.1016 / \mathrm{j}$.

62. Farzaei MH, Bahramsoltani R, Abbasabadi Z, Braidy N, Nabavi SM. Role of green tea catechins in prevention of age-related cognitive decline: pharmacological targets and clinical perspective. J Cell Physiol. 2019;234(3):2447-2459. doi:10.1002/ jcp. 27289

63. Cox CJ, Choudhry F, Peacey E, et al. Dietary (-)-epicatechin as a potent inhibitor of $\beta \gamma$-secretase amyloid precursor protein processing. Neurobiol Aging. 2015;36(1):178-187. doi:10.1016/j. neurobiolaging.2014.07.032

64. Pervin M, Unno K, Ohishi T, Tanabe H, Miyoshi N, Nakamura Y. Beneficial effects of green tea catechins on neurodegenerative diseases. Molecules. 2018;23(6):1-17. doi:10.3390/ molecules23061297

65. Russo A, Borrelli F. Bacopa monniera, a reputed nootropic plant: an overview. Phytomedicine. 2005;12(4):305-317. doi:10.1016/j. phymed.2003.12.008

66. Singh HK, Dhawan BN. Drugs affecting learning and memory. Lect Neurobiol. 1992;1:189-207. 
67. Holcomb LA, Dhanasekaran M, Hitt AR, Young KA, Riggs M, Manyam BV. Bacopa monniera extract reduces amyloid levels in PSAPP mice. J Alzheimers Dis. 2006;9(3):243-251. doi:10.3233/ JAD-2006-9303

68. Limpeanchob N, Jaipan S, Rattanakaruna S, Phrompittayarat W, Ingkaninan K. Neuroprotective effect of Bacopa monnieri on beta-amyloid-induced cell death in primary cortical culture. $J \quad$ Ethnopharmacol. 2008;120(1):112-117. doi:10.1016/j. jep.2008.07.039

69. Khan MB, Ahmad M, Ahmad S, et al. Bacopa monniera ameliorates cognitive impairment and neurodegeneration induced by intracerebroventricular-streptozotocin in rat: behavioral, biochemical, immunohistochemical and histopathological evidences. Metab Brain Dis. 2015;30(1):115-127. doi:10.1007/s11011-014-9593-5

70. Pham HTN, Phan SV, Tran HN, et al. Bacopa monnieri (L.) ameliorates cognitive deficits caused in a trimethyltin-induced neurotoxicity model mice. Biol Pharm Bull. 2019;42 (8):1384-1393. doi:10.1248/bpb.b19-00288

71. Uabundit $\mathrm{N}$, Wattanathorn $\mathrm{J}$, Mucimapura S, Ingkaninan $\mathrm{K}$. Cognitive enhancement and neuroprotective effects of Bacopa monnieri in alzheimer's disease model. $J$ Ethnopharmacol. 2010;127(1):26-31. doi:10.1016/j.jep.2009.09.056

72. Kamkaew N, Scholfield CN, Ingkaninan K, et al. Bacopa monnieri and its constituents is hypotensive in anaesthetized rats and vasodilator in various artery types. J Ethnopharmacol. 2011;137 (1):790-795. doi:10.1016/j.jep.2011.06.045

73. Saha PS, Sarkar S, Jeyasri R, Muthuramalingam P, Ramesh M, Jha S. In vitro propagation, phytochemical and neuropharmacological profiles of Bacopa monnieri (L.) Wettst.: a review. Plants. 2020;9(4):411. doi:10.3390/plants9040411

74. Kamkaew N, Norman Scholfield C, Ingkaninan K, Taepavarapruk N, Chootip K. Bacopa monnieri increases cerebral blood flow in rat independent of blood pressure. Phytother Res. 2013;27(1):135-138. doi:10.1002/ptr.4685

75. Calabrese C, Gregory WL, Leo M, Kraemer D, Bone K, Oken B. Effects of a standardized Bacopa monnieri extract on cognitive performance, anxiety, and depression in the elderly: a randomized, double-blind, placebo-controlled trial. J Altern Complement Med. 2008;14(6):707-713. doi:10.1089/ acm.2008.0018

76. Kumar N, Abichandani LG, Thawani V, Gharpure KJ, Naidu MUR, Venkat Ramana G. Efficacy of standardized extract of Bacopa monnieri (Bacognize ${ }^{\circledR}$ ) on cognitive functions of medical students: a six-week, randomized placebo-controlled trial. Evid Based Compl Altern Med. 2016;2016.

77. Thakkar VT, Deshmukh A, Hingorani L, et al. Development and optimization of dispersible tablet of Bacopa monnieri with improved functionality for memory enhancement. $J$ Pharm Bioallied Sci. 2017;9(3):208. doi:10.4103/jpbs.JPBS_8_17

78. Sharma R, Chaturvedi C. Efficacy of Bacopa monniera in revitalizing intellectual functions in children. $J$ Res Edu Ind Med. 1987;1:2.

79. Kongkeaw $\mathrm{C}$, Dilokthornsakul $\mathrm{P}$, Thanarangsarit $\mathrm{P}$, Limpeanchob N, Norman Scholfield C. Meta-analysis of randomized controlled trials on cognitive effects of Bacopa monnieri extract. J Ethnopharmacol. 2014;151(1):528-535. doi:10.1016/j. jep.2013.11.008

80. Mitra-Ganguli T, Kalita S, Bhushan S, et al. A randomized, double-blind study assessing changes in cognitive function in Indian school children receiving a combination of Bacopa monnieri and micronutrient supplementation vs. placebo. Front Pharmacol. 2017;8(NOV):1-13.

81. Morgan A, Stevens J. Does bacopa monnieri improve memory performance in older persons? Results of a randomized, placebo-controlled, double-blind trial. $J$ Altern Complement Med. 2010;16(7):753-759. doi:10.1089/acm.2009.0342
82. Joshua Allan J, Damodaran A, Deshmukh NS, Goudar KS, Amit A. Safety evaluation of a standardized phytochemical composition extracted from Bacopa monnieri in Sprague-Dawley rats. Food Chem Toxicol. 2007;45(10):1928-1937. doi:10.1016/j. fct.2007.04.010

83. Sahak MKA, Kabir N, Abbas G, Draman S, Hashim NH, Hasan Adli DS. The role of Nigella sativa and its active constituents in learning and memory. Evid Based Compl Altern Med. 2016;2016.

84. Ali BH, Blunden G. Pharmacological and toxicological properties of Nigella sativa. Phytother Res. 2003;17(4):299-305. doi:10.1002/ptr.1309

85. Rajabian A, Hosseinzadeh H. Dermatological effects of Nigella sativa and its constituent, thymoquinone. In: Preedy VR, Watson RR, editors. Nuts and Seeds in Health and Disease Prevention. Elsevier Inc.;2020:329-355.

86. Azizi Z, Ebrahimi S, Saadatfar E, Kamalinejad M, Majlessi N. Cognitive-enhancing activity of thymol and carvacrol in two rat models of dementia. Behav Pharmacol. 2012;23(3):241-249. doi:10.1097/FBP.0b013e3283534301

87. Rendeiro C, Foley A, Lau VC, et al. A role for hippocampal PSA-NCAM and NMDA-NR2B receptor function in flavonoid-induced spatial memory improvements in young rats. Neuropharmacology. 2014;79:335-344. doi:10.1016/j. neuropharm.2013.12.003

88. Hosseini M, Mohammadpour T, Karami R, Rajaei Z, Reza Sadeghnia H, Soukhtanloo M. Effects of the hydro-alcoholic extract of Nigella sativa on scopolamine-induced spatial memory impairment in rats and its possible mechanism. Chin J Integr Med. 2015;21(6):438-444. doi:10.1007/s11655-014-1742-5

89. Khan A, Khuwaja G, Khan MB. Effect of thymoquinone on streptozotocin model of cognitive impairment in rats. Ann Neurosci. 2008;15:94.

90. Alhebshi AH, Gotoh M, Suzuki I. Thymoquinone protects cultured rat primary neurons against amyloid $\beta$-induced neurotoxicity. Biochem Biophys Res Commun. 2013;433(4):362-367. doi:10.1016/j.bbrc.2012.11.139

91. Bin Sayeed MS, Shams T, Fahim Hossain S, et al. Nigella sativa L. seeds modulate mood, anxiety and cognition in healthy adolescent males. $J$ Ethnopharmacol. 2014;152(1):156-162. doi:10.1016/j.jep.2013.12.050

92. Mazzanti G, Di Giacomo S. Curcumin and resveratrol in the management of cognitive disorders: what is the clinical evidence? Molecules. 2016;21(9):1-27. doi:10.3390/ molecules 21091243

93. Al-Edresi S, Alsalahat I, Freeman S, Aojula H, Penny J. Resveratrol-mediated cleavage of amyloid $\beta 1-42$ peptide: potential relevance to alzheimer's disease. Neurobiol Aging. 2020;94:24-33. doi:10.1016/j.neurobiolaging.2020.04.012

94. Rahman M, Almalki WH, Afzal O, et al. Cationic solid lipid nanoparticles of resveratrol for hepatocellular carcinoma treatment: systematic optimization, in vitro characterization and preclinical investigation. Int J Nanomedicine. 2020;15:9283-9299. doi:10.2147/IJN.S277545

95. Feng Y, Wang XP, Yang SG, et al. Resveratrol inhibits beta-amyloid oligomeric cytotoxicity but does not prevent oligomer formation. Neurotoxicology. 2009;30(6):986-995. doi:10.1016/j.neuro.2009.08.013

96. Vingtdeux V, Giliberto L, Zhao H, et al. AMP-activated protein kinase signaling activation by resveratrol modulates amyloid- $\beta$ peptide metabolism. J Biol Chem. 2010;285(12):9100-9113. doi:10.1074/jbc.M109.060061

97. Saini RK, Rengasamy KRR, Mahomoodally FM, Keum YS. Protective effects of lycopene in cancer, cardiovascular, and neurodegenerative diseases: an update on epidemiological and mechanistic perspectives. Pharmacol Res. 2020;155 (October2019):104730. doi:10.1016/j.phrs.2020.104730 
98. Alhalmi A, Beg S, Kohli K, Waris MS. Nanotechnology based approach for hepatocellular carcinoma targeting. Curr Drug Targets. 2021;22:1.

99. Graff RE, Pettersson A, Lis RT, et al. Dietary lycopene intake and risk of prostate cancer defined by ERG protein expression. Am J Clin Nutr. 2016;103(3):851-860. doi:10.3945/ajcn.115.118703

100. Wang L, Liu S, Pradhan AD, et al. Plasma lycopene, other carotenoids, and the risk of type 2 diabetes in women. $\mathrm{Am}$ $J$ Epidemiol. 2006;164(6):576-585. doi:10.1093/aje/kwj240

101. Lei X, Lei L, Zhang Z, Cheng Y. Neuroprotective effects of lycopene pretreatment on transient global cerebral ischemia-reperfusion in rats: the role of the Nrf2/HO-1 signaling pathway. Mol Med Rep. 2016;13(1):412-418. doi:10.3892/ mmr.2015.4534

102. Zhu NW, Yin XL, Lin R, et al. Possible mechanisms of lycopene amelioration of learning and memory impairment in rats with vascular dementia. Neural Regen Res. 2020;15(2):332-341. doi:10.4103/1673-5374.265565

103. Jiang WX, Li SH, Li XJ. Therapeutic potential of berberine against neurodegenerative diseases. Sci China Life Sci. 2015;58 (6):564-569. doi:10.1007/s11427-015-4829-0

104. Asai M, Iwata N, Yoshikawa A, et al. Berberine alters the processing of alzheimer's amyloid precursor protein to decrease $\mathrm{A} \beta$ secretion. Biochem Biophys Res Commun. 2007;352(2):498-502. doi:10.1016/j.bbrc.2006.11.043

105. Zhao C, Su P, Lv C, et al. Berberine alleviates amyloid $\beta$-induced mitochondrial dysfunction and synaptic loss. Oxid Med Cell Longev. 2019;2019:1-11. doi:10.1155/2019/7593608

106. Eskelinen MH, Kivipelto M, Cunha RA, de Mendonça A. Caffeine as a protective factor in dementia and alzheimer's disease. $J$ Alzheimers Dis. 2010;20(SUPPL. s1):S167-S174. doi:10.3233/JAD-2010-1404

107. Fredholm BB, Bättig K, Holmén J, Nehlig A, Zvartau EE. Actions of caffeine in the brain with special reference to factors that contribute to its widespread use. Pharmacol Rev. 1999;51 (1):83-133

108. Lara DR, Cunha RA, de Mendonça A. Caffeine, mental health, and psychiatric disorders. J Alzheimers Dis. 2010;20(SUPPL. s1): S239-S248. doi:10.3233/JAD-2010-1378

109. Alhaider IA, Aleisa AM, Tran TT, Alzoubi KH, Alkadhi KA. Chronic-caffeine-treatment-prevents-sleep-deprivation-inducedimp-2010. Sleep. 2018;33(4):437-444. doi:10.1093/sleep/ 33.4.437

110. Duarte JMN, Carvalho RA, Cunha RA, Gruetter R. Caffeine consumption attenuates neurochemical modifications in the hippocampus of streptozotocin-induced diabetic rats. $J$ Neurochem. 2009;111(2):368-379. doi:10.1111/j.1471-4159.2009.06349.x

111. Arendash GW, Schleif W, Rezai-Zadeh K, et al. Caffeine protects alzheimer's mice against cognitive impairment and reduces brain $\beta$-amyloid production. Neuroscience. 2006;142(4):941-952. doi:10.1016/j.neuroscience.2006.07.021

112. Costa MS, Botton PH, Mioranzza S, et al. Caffeine improves adult mice performance in the object recognition task and increases BDNF and TrkB independent on phospho-CREB immunocontent in the hippocampus. Neurochem Int. 2008;53(3-4):89-94. doi:10.1016/j.neuint.2008.06.006
113. Qosa H, Abuznait AH, Hill RA, Kaddoumi A. Enhanced brain amyloid- $\beta$ clearance by rifampicin and caffeine as a possible protective mechanism against alzheimer's disease. $J$ Alzheimers Dis. 2012;31(1):151-165. doi:10.3233/JAD-2012-120319

114. Dragicevic N, Delic V, Cao C, et al. Caffeine increases mitochondrial function and blocks melatonin signaling to mitochondria in alzheimer's mice and cells. Neuropharmacology. 2012;63 (8):1368-1379. doi:10.1016/j.neuropharm.2012.08.018

115. Prasanthi JRP, Dasari B, Marwarha G, et al. Caffeine protects against oxidative stress and alzheimer's disease-like pathology in rabbit hippocampus induced by cholesterol-enriched diet. Free Radic Biol Med. 2010;49(7):1212-1220. doi:10.1016/j. freeradbiomed.2010.07.007

116. Eskelinen $\mathrm{MH}$, Ngandu $\mathrm{T}$, Tuomilehto $\mathrm{J}$, Soininen $\mathrm{H}$, Kivipelto M. Midlife coffee and tea drinking and the risk of late-life dementia: a population-based CAIDE study. $J$ Alzheimers Dis. 2009;16(1):85-91. doi:10.3233/JAD-20090920

117. Smith AP, Christopher G, Sutherland D. Acute effects of caffeine on attention: a comparison of non-consumers and withdrawn consumers. J Psychopharmacol. 2013;27(1):77-83. doi:10.1177/ 0269881112460112

118. Vercambre MN, Berr C, Ritchie K, Kang JH. Caffeine and cognitive decline in elderly women at high vascular risk. J Alzheimers Dis. 2013;35(2):413-421. doi:10.3233/JAD-122371

119. Lindsay J, Laurin D, Verreault R, et al. Risk factors for alzheimer's disease: a prospective analysis from the Canadian Study of Health and Aging. Am J Epidemiol. 2002;156(5):445-453. doi:10.1093/aje/kwf074

120. Gelber RP, Petrovitch H, Masaki KH, Ross GW, White LR. Coffee intake in midlife and risk of dementia and its neuropathologic correlates. $J$ Alzheimers Dis. 2011;23(4):607-615. doi:10.3233/JAD-2010-101428

121. Corder EH, Saunders AM, Strittmatter WJ, et al. Gene dose of apolipoprotein E type 4 allele and the risk of Alzheimer's disease in late onset families. Science. 1993;261(5123):921-923. doi: $10.1126 /$ science. 8346443

122. Van Boxtel MPJ, Schmitt JAJ, Bosma H, Jolles J. The effects of habitual caffeine use on cognitive change: a longitudinal perspective. Pharmacol Biochem Behav. 2003;75(4):921-927. doi:10.1016/S0091-3057(03)00171-0

123. Rho S, Kang M, Choi B, et al. Effects of Yukmijihwang-tang derivatives (YMJd), a memory enhancing herbal extract, on the gene-expression profile in the rat hippocampus. Biol Pharm Bull. 2005;28(1):87-93. doi:10.1248/bpb.28.87

124. Liu JX, Cong WH, Xu L, Wang JN. Effect of combination of extracts of ginseng and ginkgo biloba on acetylcholine in amyloid beta-protein-treated rats determined by an improved HPLC. Acta Pharmacol Sin. 2004;25(9):1118-1123.

125. Kang SY, Lee KY, Koo KA, et al. ESP-102, a standardized combined extract of Angelica gigas, Saururus chinensis and Schizandra chinensis, significantly improved scopolamine-induced memory impairment in mice. Life Sci. 2005;76(15):1691-1705. doi:10.1016/j.lfs.2004.07.029 


\section{Publish your work in this journal}

Degenerative Neurological and Neuromuscular Disease is an international, peer-reviewed, open access journal focusing on research into degenerative neurological and neuromuscular disease, identification of therapeutic targets and the optimal use of preventative and integrated treatment interventions to achieve improved outcomes, enhanced survival and quality of life for the patient. The manuscript management system is completely online and includes a very quick and fair peer-review system. Visit http://www.dovepress.com/ testimonials.php to read real quotes from published authors.

Submit your manuscript here: http://www.dovepress.com/degenerative-neurological-and-neuromuscular-disease-journal 